\title{
Luxury Retail - The Online Experience
}

\author{
Cristina de Azevedo Rosa* \\ Instituto Universitário de Lisboa (ISCTE-IUL), Portugal
}

*Corresponding author: Cristina de Azevedo Rosa, Department of Marketing, Operation and Management, ISCTE-Instituto Universitário de Lisboa, Portugal.

\author{
Received Date: April 10, 2019 \\ Published Date: May 03, 2019
}

\begin{abstract}
The concept of luxury is as old as humanity even if over time meant different things, luxury is a conceptual and symbolic dimension and it is today the result of a historical evolution. Luxury is mainly irrational and engages strong and intense emotions, it is multisensory. "Luxury is above all a world of brands" Philip Kotler. The luxury brands go beyond the object: they are built from the reputation made from their creations within the social elites and trendsetters. The major conclusion Professor Dubois studies is that consumer attitudes and behavior towards luxury are ambivalent following an attraction/avoidance pattern (sometimes occurring within the same person). The watchword for luxury is experience and the shop is where the client lives the brand. Professors Bastien and Kapferer presented 4 modes of distribution [3], each one more suitable (than the others) according to the products/services and/or the markets where the luxury brand operates. To be able to be successful in selling luxury online, luxury brands have to build and implement an e-business strategy, the model presents 10 tactical important aspects. Today the world faces an uncommon and violent turbulence; severe crisis in Europe, instability in United States and accelerated growth in BRIC countries (Brazil, Russia, India and China) and soon in the CIVETS's (Colombia, Indonesia, Vietnam, Egypt, Turkey and South Africa). However, the extraordinary results of the most important luxury groups are encouraging and reveal that so far challenges have been transformed in great opportunities. This paper has been adapted and updated from sections of the book, translation: Luxury Empire - Building Success.
\end{abstract}

Keywords: Luxury; Brands; strategy; Customer; E-retail; Success

\section{Introduction}

The concept of luxury is as old as humanity even if over time meant different things, luxury is a conceptual and symbolic dimension and it is today the result of a historical evolution [1]. The word luxury comes from the word in Latin "Luxus" which had its origin in agriculture, and it meant "exceeding growth" and became the word for exceeding in general; only in the 17th century did it acquire the significance that it has today [2].

Luxury is mainly irrational and engages strong and intense emotions, it is multisensory [3]. All definitions end in concepts of beauty, exquisiteness, perfection, pleasure, excellence, elegance, sophistication and exclusivity but also superiority, power, authority, distinction, ostentation, etcetera.

The Sociovision Confremca institute elaborated an international study [2] and revealed that luxury can be characterized by being distant, desired, merited, and providing a sensation of recompense, recognition and reward [2]. Still according to this worldwide study, luxury offers an emotional sensation of calm and tranquility in the moment of consumption. Luxury is experienced as a gathering between the "object" and a personal and private meaning of luxury which provides pleasure, comfort and harmony. Luxury is qualitative and not quantitative. For instance, the number of diamonds in a watch indicates its opulence not its beauty or aesthetics [3].

\section{Luxury}

"Luxury is something that we do not need but we cannot do without" Jean Louis Queimado - Vacheron Constantin Iberia [4].

Luxury is a culture and a philosophy and therefore requires deep understanding before the adoption of business practices because its particulars are fundamentally different from other types of goods [5]. The original function of Luxury is rooted in the social classes of societies when royals and aristocrats used pretentious consumption to demonstrate their superiority and maintain their distance from "others". Even if this social structure is no longer dominant in the world the need for the individual to show his distinction, to be admired, recognized, appreciated and respected through differentiating himself in most cases with his possessions [5], has not changed.

Today the concept of luxury has changed profoundly, and it is incredibly fluid; luxury is no longer preserved for elite, people are enjoying more material comfort resulting in a cultural shift for personal achievement and aspiration through experience 
[6]. Therefore, it could be assumed that luxury is more and more about experience and authenticity rather than monetary value. This focus on aspiration and experience means that consumers want to improve their life mainly through personal transformation. The feminization of luxury was identified by Danziger, Israel and Gambler as; where luxury was moved from status symbols towards experience and indulgence [6].

Professor Kapferer estimated the luxury market to be 2 trillion of Euros in 2010 [3] and as Bernard Arnault, founder and CEO LVMH (Louis Vuitton Moet Hennessy), said clearly: "Luxury is the only sector that can provide luxurious margins" [7].

\section{Luxury Brands}

"Luxury is above all a world of brands" Philip Kotler [4].

The father of Marketing Mix - "The 4 P's" - provoked a revolution in the 50's with his model centered on the product with little competition. In those days' brands weren't important. In the 70's, brand appears as an additional element to the product but after the 90 's of the last century, brands took the power and became a recognized signature with individuality and unique characteristics expressed by products and services [8].

Therefore, it is easy to accept that there is no luxury without brands3. The exception that confirms this rule is diamonds which are loved and admired in themselves, their nature size and purity, even if the jeweler is often a prestigious and luxury brand.

"Luxury objects are objects of luxury brands." [3]

The luxury brands go beyond the object: they are built from the reputation made from their creations (objects and services) within the social elites and trendsetters. A recognized signature of all the stunning and beautiful distinction in the product and service, thereby the luxury brand has particular significance: it relates a social and cultural stratification and makes the wearer someone distinctive. Consequently, the luxury brand is a social indicator and creates distance [3]

Brands in luxury are most relevant since they are used as a social marker. In democracy people are free and equal, so they use components to differentiate themselves socially [3]. Within the limit of their financial means, they employ luxury as an instrument of social stratification. Consequently, luxury brands are a symbolic desire to belong to a social class, most of the time superior, even if this aspiration is rarely assumed.

Money only measures the wealth of the buyer and not his/ her elegance. However, the codes of luxury are cultural and to be successful it is fundamental for luxury brands to first encode social distinction, that way luxury brands exchange money into a culturally sophisticated social stratification [3]. The luxury brand is therefore the social and cultural visa for the product and the person.

A luxury brand is often a signature of the person whose name it bears, its founder9. The creator precedes the brand, has a history and social, cultural and geographical roots therefore the luxury brand is a real and living person. Like it is foundering the luxury brand progressively builds its reputation and its network of followers over time [3]. Gabrielle Chanel died in 1971 but Coco Chanel is still living.

\section{Luxury Consumer}

"There are two ways to go bankrupt: not listening to the client and also listening to him too much" [3].

It is crucial to listen (impartially) to the customer and never forget that "you" are not the customer. However, luxury brands must remain truthful to them and resist client's demands when these do not correspond to the precise vision of the luxury brand [3].

Today consumers contradict themselves and confuse the best market research because they are a complex and ambivalent. It is essential to listen, interact and serve the consumer; this is the focus and the foundations for success and competitiveness of luxury brands [9].

In Professor's Bernard Dubois (and colleagues) research [10], consumer attitudes towards luxury were analyzed and several characteristics, attitudes and types of consumers were identified. This important research brought relevant information about the luxury consumer.

In the first study (personal interviews) six facets and characteristics of luxury emerged [10]:

\section{Excellent quality}

The mental association between luxury and quality is powerful and sometimes synonymous. Consumers use two indicators to build their opinion: exceptional nature of the materials or components used, and the delicacy and skill involved in the manufacturing and delivery processes. They also feel it is an opportunity to become refined, unique and joyful;

\section{Very high price}

By comparison with non-luxury options or based on the absolute value of price, it is considered a logical consequence of the excellent quality associated with luxury and it is an inherent and accepted characteristic

\section{Scarcity and uniqueness}

Clearly, real luxury items cannot be mass-produced and should have restricted distribution. Luxury shops are perceived as important sources of experiences and therefore value. Luxury should be unique and reserved for a "happy few" providing exceptional experiences and emotions;

\section{Artistic and "polisensuality"}

Luxury is perceived as an experience for the senses; beautiful to look at, pleasant to hear, smell, taste or touch. It implies a selfconcept of delight and happiness; 


\section{Ancestral heritage and personal history}

Luxury brands need to have a legend or a story to tell. Anchoring in the past sustains a long relationship and feeds confidence. Tradition and longevity create immortal symbols of human creativity and intelligence;

\section{Superfluousness}

Luxury's first attribute is that it is not useful; on the contrary its value must be based on nonfunctional qualities.

The second study [10] was based on the above identified characteristics towards luxury and consumer attitudes and consisted in a large survey ( 20 countries) to identify the groups or segments of luxury consumers.

For all the respondents' luxury was perceived as being of better quality and pleasant, it is bought with pleasure and revealing of whom the individual is. It was possible to categorize three types [10] of groups:

\section{Elitist's group}

Luxury is good and must be reserved to a small refined, sophisticated and educated (them, likely) elite. Luxury implies "good taste" and allows them to differentiate from others. It is certainly very expensive and can't be mass-distributed;

\section{Democratic group}

Tend to think that luxury must be easily accessible to people and can be mass-distributed. To appreciate luxury goods no special education is required, and this group do not see luxury as being reserved to refined people. In addition, they consider that it is not a synonym of good taste or an instrument of differentiation and it does not necessarily have to be very expensive. This group is very positive towards luxury;

\section{Distant group}

Even if they do not have a markedly negative attitude to luxury, they feel it is "another" world in which they do not belong. Personally, they are not attracted to luxury, they do not identify any attribute, value or relevance to it, and they think it is useless, too expensive and suggest that luxury should pay more taxes.

A major conclusion of both studies is that consumer attitudes and behavior towards luxury are ambivalent following an attraction/avoidance pattern (sometimes occurring within the same person). However, the most important characteristics are quality, self-indulgence and ancestral heritage, these attributes define luxury to consumers and are fundamental to communicate with them.

"For me luxury derives from three key factors: exclusivity, quality and brand, and in that order of importance. I buy luxury because it gives me pleasure and because I can, up until certain levels of course, and depending on the nature of the goods. My last purchases were: Louis Vuitton's glasses, Carolina Herrera's clothing and Loewe's accessories. The reason I bought it was because it gave me pleasure to buy them even though I did not need any of them. Some were gifts." Vasco Marques Correia, luxury consumer [11].

\section{Luxury Distribution}

The watchword for luxury is experience and the shop is where the client lives the brand. Worldwide the most beautiful streets are being transformed into luxury streets; it is the materialization of the key role of distribution in luxury [3].

\section{People}

As said before most people seek ways to climb up different levels, be these: cultural, social, economic, etcetera. Luxury is one of the ways to achieve this goal and luxury brands are its tool. To preserve its status, the luxury brand must dominate its client in the sense that it is a reference and an authority to him or her [11]. In order to be successful, it is essential to achieve a perfect balance between a distant and mysterious connection with a trustful and intimate relationship with the customer.

Therefore, it is imperative to establish a permanent dialogue between customer and brand, known as "image through action" [12]. The luxury brands tell their story and the accuracy as the story that is told by others defines the success of the relationship. The luxury brand has the responsibility to begin and feed a personal connection with the client and will be capitalized by the consumer's per-to-per communications [11]

A personal, almost affective, relationship must be created between the brand and the customer [3] since a luxury product/ service is passed on, rather than sold. This one-to-one relationship is a key factor for the success of the luxury brand.

"You sell to someone before you sell something." [4]. That is why human resources are vital in luxury; everyone is a permanent "ambassador" of the brand (from the CEO to the doorman) [4].

The most prestigious luxury brands devote much attention and investment to the education and training of their employees [4]. It is crucial to create and feed a personal, emotional and affective relationship between the customer and the "ambassador". The success of the established relationships is materializing by brand loyalty and purchase.

The "stratification" of modern fashion designers is an important requirement if luxury brands want to reach larger audiences. These designers are leaders who take their followers into the world of style, creative culture, taste and sensory experience so fare restricted to the elite [7].

In our impersonal and cold world customers look for attention, consideration, friendship and someone who they can trust. The "ambassador" must congregate all these requirements (and more) to be successful in his goal which is to: "make the customer happier", because a pleased client is a loyal one and most important of all, himself he becomes a positive "ambassador" to potential clients. 
Personal advice in the luxury world is imperative, most of the time the customer looks for advice from the people he trusts. The "ambassadors" fulfill this role and the luxury brand will be as successful as the quality of his ambassadors (internal and external) [4]. Most of the time the customer enters the boutique with no idea of what he/she will buy and often they place their trust entirely on the "ambassador". Therefore, the permanent training and the stability of the luxury boutique staff is of great importance.

Distribution must be done in a secure and calm environment Remember that the client is buying; it is not the luxury brand who is selling. The luxury brand effect on its own is not enough to build brand loyalty and proper brand management specially focuses on brand trust and is necessary to successfully maintain longer-term customer relationships [13].

\section{Price}

In a luxury boutique no price is visible; clearly the focus is the product, like in an art exhibition where the pieces are exhibited.

"The price is the exchange value of a product, but what makes luxury is the "symbolic value" [3]. Nevertheless, the price is still a decisive operational decision and it is fundamental to understand the competitive environment and to "perfectly" balance both function and dream.

Customers expect luxury to be expensive, high price creates a barrier of entry, increases exclusivity and desire [14]. By increasing prices luxury brands lose the bad clients and became interesting for others11, however the brand must be careful not to fall into a niche. In a focus group a nouveau riche Chinese man said: "What I like about luxury is that it is expensive." [7]

Once again, the role of the "ambassadors" is crucial. When the price is asked, they will begin by pointing the refined details, quality materials, exceptional design, etcetera. The mission of the "ambassador" is to make the client understand and share the mystery, the charm, the magic of the place, the object and the time personified in each item. Eventually, in the end they inform the customer about the price. In fact, what the "ambassador" really sells is the price not the object or service [3].

The price must preserve some secrecy. Therefore, all communication must try to position the product at the highest possible level without directly mentioning the price. That is one of the difficult aspects for luxury fashion brands on using the internet as a distribution channel [3].

\section{Communication}

A luxury brand never communicates the price directly [3]. Consequently, the distribution must communicate the price to the customer in two ways: the luxury boutique communicates the price level and the "ambassador" indicates the exact price to the client.

Distribution is communication; the store is not only the screen for the projection of the luxury brand's history but also a representation that places the object of desire at a distance in order to increase desire. The window of a luxury boutique is a privileged place and a major tool of public communication; it is a good way to make non customers aware of the status of the brand and contribute to the dream equation.

Andy Warhol said [3] "someday all department stores will become museums and all museums will become department stores". Even if controversial this affirmation predicted the development of the great luxury brands into many luxury universes within the brand and to the concept of "megastore" that combines the coherence of all the brand universes, on the other hand the "store concept" reveals the brand's evolution and accompanies it.

\section{Luxury retail}

Luxury is luxury because it is rare and reserved to a "happy few". Part of the rarity present in luxury brands is a consequence of their conception such as: precious raw materials, manual work by specialized artisans and artistic design. It can (and it must) also be created by managing rarity and selectivity in distribution: few sales points, precise locations, and quality sales personnel, boutiques as a showcase and merchandizing as staging for the product. Last Christmas when Louis Vuitton reduced the opening hours of its boutiques worldwide, they created rarity and desire by limiting the time to buy their products.

So, it is accurate to say that the retail marketing models organize and govern not only the ways in which luxury is materialized and expressed (in different cultural contexts) but also, they organize and manage the access to luxury [15].

Professors Bastien and Kapferer presented [4] modes of distribution [3], each one more suitable according to the products/ services and/or the markets where the luxury brand operates:

The own brand store is the most natural and consistent with the origin of luxury and the notion of personal relationship. In this option the brand is in total control; products, service, price, image, etcetera. The luxury brand knows exactly, and immediately which products are selling and consequently providing a high economic efficiency. The human aspect is clearly the most important advantage because the "ambassadors" (sales personnel) are really part of the brand and the quality relationship between client and ambassador is very strong. However, it is a rigid method, it presupposes an important investment, a reactive and anticipatory management as well as a stable product range. To be profitable it presumes that the product or service can be sold in enough quantities, and it can be challenging. Louis Vuitton is the master of this kind of distribution.

Exclusive distribution: This mode is appropriate when an important quality sales network already exists, and the product has strong after-sales constraints that require a vast network; the best-known examples are automobiles and watch-making. The distribution agreement must define the specified location and personnel but also be totally transparent regarding the customers 
and the conditions established. The biggest advantage compared with the previous mode is that this structure is more flexible, simple to complement with a mixed network without damaging the luxury brand and easy to make it profitable (overheads are shared with other brands). Rolex is a successful example.

Selective distribution: In this case the luxury brand no longer decides its distribution network. In the European legal context, any sales point that respects the brand's specifications is a potential distributor. Even if the brand's codes are protected, the direct link between the customers and the luxury brand is broken because they are clients of the "sales point" and no longer of the luxury brand. Professor Kapferer says that is the first step towards departure from the luxury universe [3]. Indeed, the line that differentiates luxury from premium is easily lost. Nevertheless, this method allows diffusion of the products without making it common and it is advisable for luxury brands with wide distribution and frequent purchase such as perfume and cosmetics. However, be aware that in this mode it is difficult (almost impossible) to control the sales points in terms of brand's code, price and image.

At-home sales: Finally, this was the original mode of sale for luxury; the artisan travelled to the customer to take their order and then to deliver it. The haute joaillerie is still a good example.

\section{e-Luxury Retail Strategy}

Since the internet came along luxury is no longer viewed in the way it used to be in the past. Luxury websites can be accessed by anyone, anywhere and at any time (7 days a week, 24 hours a day). Information about luxury products and services is diffused online as soon as they are launched and often even before they hit the stores. The images and runway luxury brands frequently show up on blogs and e-communities before they do so on media websites or on the official websites of the brands.

The internet is viewed by many as one of the most effective means to reach sales targets [16]. Its relative cost-effectiveness coupled with a wider reach and extensive data- capturing capabilities has made e-retail appealing to luxury brands. Some of the luxury brands use their e-boutiques to expand their range online.

To be able to be successful in selling luxury online, luxury brands must build and implement an e-business strategy and a plan that will develop all aspects of their web presence [16]. Luxury e-business strategy doesn't have to begin with e-retail. In fact, the ideal approach of e-retail would be to follow a methodical process of launching an appealing website with rich and interactive content and incorporate the e-boutique within this environment.

In 2011, Louis Vuitton started its own digital in-house agency, a team of 400 people, mostly the best professionals in the market [7]. Its goal is to diffuse content about the brand all over the world, including history, heritage, craft details, PR events, imaginative interviews, fashion shows, inventive travel guides, etcetera. The e-boutique launches products and services [7] and presents not only the current collections but also exclusive editions and products.

Louis Vuitton's example should clearly be watched and be an inspiration to other luxury brands whether they are focused on High Fashion or not, as it provides key learning on how luxury brands can master the art of social media [5]. Their success is evidently the consequence of an important investment in a permanent reinvented digital communication and distribution with worldwide actual, future and aspiring customers.

The Okonkwo U [16] model for an integrate luxury e-retail strategy follows a number of tactical choices:

The location choice: The first assessment is to define the markets that the e- retail activity will serve. This definition could range from countries, regions and states and will therefore affect connected issues like legal issues, currency, pricing, warehousing, transport and after-sales. Although the internet is global in reach and the ideal choice would be worldwide distribution, it is not always possible due to regulations, logistics and other factors. The internet is the most cost-effective means of luxury retail and this advantage should not be damaged.

Production selection: Identifying the right products is very important. The choice of the products to sell online should follow the strategic objective of e- retail for the brand. Armani began to test the market by placing only a few items, Hermès chose their e-boutiques to be outlets, but Louis Vuitton and Gucci have a wide product range available online as in their shops. Product selection should also follow the peculiarities linked to shipping and security.

Pricing approach: Internet does not mean necessarily low prices and discounts. For example, Louis Vuitton does not practice price reductions and applies this principle online too. Luxury brands need to have a coherent pricing approach online and offline to accord with client's expectations.

e-boutique development: Creating an attractive and interesting e-boutique is fundamental. The luxury customers expect online to be a world of discovery and immersion into the brand universe, they expect to find stimulating and engaging virtual surroundings. As described in the Louis Vuitton example above, web elements and e-tools are to be included in the entire website and not only in the e-boutique, it is a total experience. Consumers expect luxury brands to be distinct in their e-shopping environment.

e-tools incorporation: Like zoom, 3-D, spin and flip; e-merchandising tools like personal avatars and virtual models; e-customization items like product drawing and co-creative software; as well as client management tools like companion shopping applications and virtual shopping assistants. These tools ensure that the web experience is rich and that customers receive the level of commitment they expect.

Service optimization: The internet provides one of the best opportunities to serve luxury consumers in a personal and 
intimate way. With the access of data capturing applications that allow the recognition of customers and the presentation of their habits, preferences and shopping histories, luxury brands have all the elements to pursue a personalized relationship with online clients. Today technology permits to assist consumers in the online shopping experience by offering styling tips, advice on collections and care guides. Online consumers expect to be able to chat instantly with virtual shopping "ambassadors" who understand their needs and can provide style solutions. The service expectations include several options to instantly connect with a real sales representative by phone, email, chat, call-back or voice messaging systems. Every online element that can contribute to a memorable shopping experience must be added by the luxury brand.

Back-office support: Luxury e-boutiques contents are expected to be rich and image-heavy with advanced interactive applications, those elements require a solid back-office system. The e-stores must always be projected to function flawlessly and are not expected to close for maintenance. Luckily advanced technology has been able to offer systems that allow the upgrading of website while keeping it running.

Client management: The goal of every luxury e-retail website is to fulfill and exceed online luxury customer's expectations. Bombarding clients with standard emails containing irrelevant information may cause irritation and annoyance. It is imperative to have an integrated approach; creative and cross-communication that are both interactive and engaging because the real online consumer must be reached, enchanted, surprised and informed through rich content and be affiliated with a two-way exchange.

Modeling the e-retail: The choice of a model for e-retail is crucial for sales optimization and brand position. The ideal e-retail model for a luxury brand is the integration of an e-boutique that features the appropriate product range to meet the define objectives of the e-retail. Some will decide to sell under-performed items others will decide for a sales revenue generation purpose.

Channel integration: The most important challenge is connected to the combination of every aspect of the two main retail channels: offline and online across product selections and merchandizing; in-store service and after sales; customers traffic, data collections and management; sales performance, targets and estimates. The progressive importance of the dual retail channel is strengthened by an increasingly international clientele. It is common for a luxury brand to have a shopper who not only shops at the brand's stores in different locations (London, Singapore, Milan, New York, etcetera) but also online. The desirable integration of information collected on this client in the different selling channels is the secret to feed a perfect and very fruitful relationship between the luxury brand and the client. Channel integration must also extend store services to include aspects of the after sales services such as returns, exchanges, refunds and repairs. It is important to allow clients to reserve items in a store from the website or book store appointments online.

\section{The Future}

Today the world faces an uncommon and violent turbulence; severe crisis in Europe, instability in United States and accelerated growth in BRIC countries (Brazil, Russia, India and China) and soon in the CIVETS's (Colombia, Indonesia, Vietnam, Egypt, Turkey and South Africa). In these countries, gross domestic product (GDP) growth is high and it is a fine prospect for luxury fashion brands, because as Bernstein Research [7] revealed luxury market growth is closely correlated with GDP growth because it creates or increases middle class and promotes optimism. These nations developed consumption society's quite late, people advance by leaps and claim their right to success and therefore are eagerly looking to spoil themselves by acquiring luxury fashion brands.

In order to benefit from the increasing demand for luxury goods in those countries major luxury retailers are now occupied in a very vibrant store-expansion strategy. Louis Vuitton announced that it would enter the provincial capitals in China to attract more customers; in the beginning of 2012 [7], the luxury brand had 37 stores across 29 cities in China. Naturally this decision is motivating other luxury brands (Gucci, Coach, Burberry and others) to open stores in these cities. However, in their retail expansion strategy [7] luxury brands must constantly maintain the balance of the crucial equation luxury = rarity, which is of utmost importance to preserve the high prices charged. "When one of our products gets too successful, we stop (selling) it" said Patrick Thomas CEO of Hermès [17].

The luxury fashion companies that successfully prove the exclusive qualities of their brands (products and services), their irrefutable heritage, their refined creativity, their astonishing innovation and their unique experience will pass through beautifully and will emerge stronger than never. It is a continuous regenerating process at all levels. It may seem contradictory, but luxury fashion brands must go back to their roots and renew the magic and beauty of the brand by reinforcing the myth through permanent creativity and innovation. The luxury fashion consumer must be seduced constantly.

In fact, the extraordinary results of the most important luxury groups are encouraging and reveal that so far challenges have been transformed in great opportunities.

\section{Acknowledgement}

None.

\section{Conflict of Interest}

No conflict of interest

\section{References}

1. Luzzini D, Ronchi S (2010) Purchasing management in the luxury industry: organization and practices. Operations Management Research 3(1-2): 7-21.

2. Lipovestsky G, Roux E (2004) El lujo eterno. Anagrama.

3. Kapferer JN, Bastien V (2009) The Luxury strategy. Kogan Page. 
4. de Azevedo Rosa C (2010) Império do Luxo. Lidel

5. Okonkwo U (2009) Sustaining the luxury brand on the internet. Journal of Brand Management 16(5-6): 302-310.

6. Yeoman I (2010) The changing behaviors of luxury consumption Macmillan Publishers Journal of revenue and pricing management. Journal of Revenue and Pricing Management 10(1): 47-50.

7. Kapferer JN (2012) Abundant rarity: the key to luxury growth. Business Horizons 55(5): 455-463.

8. Chevalier M, Mazzalovo G (2008) Management et Marketing du Luxe Dunod

9. Garcia SC (2003) El universo del lujo. Instituto de empresa McGrawHill.

10. Dubois B, Laurent G, Czellar S (2001) Consumer rapport to Luxury: analyzing complex and ambivalent attitudes. Cahier de recherche no 736.
11. Kapferer J.N, Bastien V (2009) The specificity of luxury management: Turning marketing upside down. Journal of Brand Management 16(56): 311-322.

12. Winsper J (2007) The 6 P's of Luxury marketing. Winsper Inc.

13. Song Y, Hur WM, Kim M (2012) Brand Trust and affect in the luxury brand-customer relationship. Social behavior and personality $40(2)$ : 331-338.

14. Fionda AM, Moore CM (2009) The anatomy of the luxury fashion brand. Journal of Brand Management 16(5): 347-363

15. Dion D, Arnould E (2011) Retail Luxury Strategy: assembling charisma through Art and Magic. Journal of Retailing 87(4): 502-520.

16. Okonkwo U (2010) Luxury Online. Palgrave macmillan.

17. Kapferer JN (2010) Luxury after the crisis: Pro logo or not logo? European Business Review. 